\title{
Investigation of interaction effect between static and rolling friction of corn kernels on repose formation by DEM
}

\author{
Linrong Shi, Xiaoping Yang, Wuyun Zhao*, Wei Sun, Guanping Wang, Bugong Sun \\ (College of Mechanical and Electrical Engineering, Gansu Agricultural University, Lanzhou 730070, China)
}

\begin{abstract}
The coefficient of static friction (SF), the coefficient of rolling friction (RF) for particles are two key parameters affecting the repose angle formation and flow characteristics. In this paper, the interaction effects of SF and RF on the formation process of corn repose angle was investigated by the discrete element method. Firstly, five shape kinds of corn models (horse tooth, spherical cone, spheroid, oblate, and irregular shape) were established. Secondly, aluminum cylinder and organic glass box were used to conduct the simulation experiments with taking SF and RF as independent factors and seeing the repose angle as dependent value. Based on simulation results the regression equations were established. Simulation results showed the relation between two factors and the rotational kinetic energy is not nonlinear, and SF does not significantly restrict the flow of corn models after increasing the flow direction, and the effect of SF on the contact number between corns and the bottom plate is remarkable, while the effect of RF on the contact number is not remarkable. Finally, the interaction effect of two factors on the repose angle was analyzed by variance analysis and results showed SF and RF all have a significant impact on the repose angle. Moreover, their interaction effect has an impact on the repose angle.
\end{abstract}

Keywords: corn kernels, coefficient of static friction, coefficient of rolling friction, repose angle, interaction influence DOI: $10.25165 /$ j.ijabe.20211405.4357

Citation: Shi L R, Yang X P, Zhao W Y, Sun W, Wang G P, Sun B G. Investigation of interaction effect between static and rolling friction of corn kernels on repose formation by DEM. Int J Agric \& Biol Eng, 2021; 14(5): 238-246.

\section{Introduction}

The repose angle is often used to calibrate material parameters in agricultural engineering, such as seeds and soil. In recent years, The discrete element method (DEM) is adopted to investigate the flow characteristics of particle materials, nowadays, which is widely applied in the field of agricultural equipment ${ }^{[1-4]}$. The main factors affecting the formation of repose angle include the particle shape, friction characteristic, the contact model and so on. Particle shape is more likely to impact the formation of repose angle with the tangential force than the normal contact force ${ }^{[5]}$. Increasing sphericity and convexity can significantly decrease the angle of repose. The non-spherical ballast model gives a more realistic angle of repose behaviors compared to simply particle models ${ }^{[6]}$. On the other hand, the coefficient of static friction, rolling friction also are two key parameters affecting the formation of repose angle, flow characteristics ${ }^{[7]}$. Among them, the coefficient of static friction has a significant effect on particles velocity distribution, porosity distribution, collision frequency, collision energy, and power draw in an IsaMill ${ }^{[8]}$. That between particle and cylinder sieve wall mainly affects the axial motion

Received date: 2019-12-04 Accepted date: 2021-06-21

Biographies: Linrong Shi, $\mathrm{PhD}$ candidate, Experimenter, research interests: research on key technologies and equipment for precision seeding in Northwest Cold and Arid Zone, Email: shilr@gsau.edu.cn; Xiaoping Yang, Associate Professor, research interests: agricultural mechanization engineering, Email: yangxp@gsau.edu.cn; Wei Sun, Professor, research interests: agricultural mechanization engineering, Email: sunw@gsau.edu.cn; Guanping Wang, Associate Professor, research interests: agricultural electrical engineering, Email: wangguanping@gsau.edu.cn; Bugong Sun, Professor, research interests: agricultural mechanization engineering, Email: sunbg@gsau.edu.cn.

* Corresponding author: Wuyun Zhao, $\mathrm{PhD}$, Professor, research interests: farm machine and mechanical reliability. College of Mechanical and Electrical Engineering, Gansu Agricultural University, Lanzhou 730070, China. Tel: +86-451-7632472, Email: zhaowy@gsau.edu.cn. while that between particles primarily influences the circular motion in milling process ${ }^{[9]}$. However, the repose angle increases linearly with increasing coefficient of rolling friction of corns ${ }^{[10]}$, while the gap between the boundary circle and the continuous circle decreases $^{[11]}$. The accuracy of measuring the coefficient of static and rolling friction is confirmed using the repose angle and the discharge velocity of a hopper ${ }^{[12]}$. A rotating drum apparatus is used to analyze the repose angle and flow characteristics of black pepper with DEM, the coefficient of static friction between particles and the coefficient of rolling friction between particle and wall all has remarkable impact ${ }^{[13]}$. The influence of the coefficient of rolling friction on the formation process of repose angle of flax seeds was analyzed with EDM, and with decreasing the coefficient of rolling friction, the contact number between flax seeds and bottom plate increase, while the rotational kinetic energy increase first and then decrease ${ }^{[14]}$. The above research was conducted to study the effect of only one factor (the coefficient of static friction or the coefficient of rolling friction) on the formation process of repose angle. However, there are no relevant studies yet about the interaction effect between them on the formation process of repose angle.

Based on the results of the previous study ${ }^{[7]}$, the interaction effects of the inter-corns coefficient of static and rolling frictions on the repose angle of corn kernels were investigated with DEM based on binary quadratic mathematical regression models. In addition, the effect of them during the formation process of corn models on the rotational kinetic energy, the contact number are studied in detail.

\section{Materials and methods}

\subsection{Model and parameters}

2.1.1 Contact model

The corn variety of Longdan No.5 was selected as experiment material. Its water content is $13.2 \%$, measured with drying 
method (drying oven, DHG-9013A, Shanghai Yiheng Instruments Ltd., China). The cohesion between corn kernels, the adhesion between corn kernel and contact material can be ignored because of its low water content. Therefore, Hertz-Mindlin (no-slip) in EDEM 2018 software (Engineering discrete element method, DEM Solution Ltd) was selected to simulate the formation process of corn models ${ }^{[15]}$. According to the combination of forces and the loss of energy in particle contact collision, the collision contact forces and damping of each particle are decomposed into force in the normal and tangential direction in the model ${ }^{[16]}$, as shown in Figure 1. Through iterative coupling calculation and analysis, the position of particles in the simulation time can be obtained.

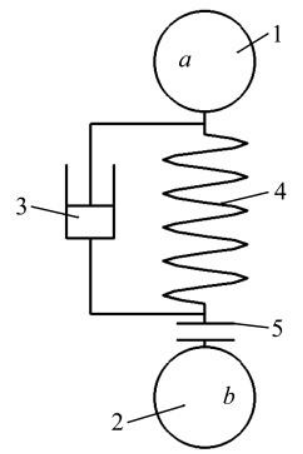

Normal contact model

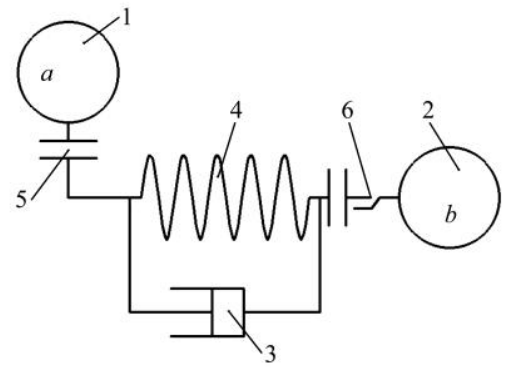

Tangential contact model $\begin{array}{llll}\text { 1. Particle } a & \text { 2. Particle } b & \text { 3. Damper 4. Spring 5. Coupling 6. Slider }\end{array}$

Figure 1 Contact model of Hertz-Mindlin

The normal and the tangential contact force in the contact model are, respectively.

$$
\begin{gathered}
F_{n}=\frac{4}{3} E_{0} \sqrt{R_{0} \alpha^{3}} \\
F_{t}=-S_{t} \delta
\end{gathered}
$$

where, $\frac{1}{E_{0}}=\frac{1-v_{1}^{2}}{2 G_{1}\left(1+v_{1}\right)}+\frac{1-v_{2}^{2}}{2 G_{2}\left(1+v_{2}\right)}, \frac{1}{R_{0}}=\frac{1}{R_{1}}+\frac{1}{R_{2}} ; F_{n}$ is the normal contact force, $\mathrm{N} ; E_{0}$ is the equivalent elastic modulus, $\mathrm{Pa}$; $R_{1}, R_{2}$ is the radius of contact sphere, $\mathrm{m} ; R_{0}$ is the equivalent contact radius, $\mathrm{m} ; \alpha$ is the normal overlap, $\mathrm{m} ; G_{1}, G_{2}$ is the elastic modulus of two particles, respectively, $\mathrm{Pa} ; v_{1}, v_{1}$ is Poisson's ratio of two particles; $S_{t}$ is the tangential stiffness, $\mathrm{N} / \mathrm{m} ; \delta$ is tangential overlap, $\mathrm{m}$.

The normal and tangential damping force are, respectively.

$$
\begin{aligned}
F_{n}^{d} & =-2 \sqrt{\frac{5}{6}} \frac{\ln \varepsilon}{\sqrt{\ln ^{2} \varepsilon+\pi^{2}}} \sqrt{S_{n} m_{0}} v_{n}^{\text {rel }} \\
F_{t}^{d} & =-2 \sqrt{\frac{5}{6}} \frac{\ln \varepsilon}{\sqrt{\ln ^{2} \varepsilon+\pi^{2}}} \sqrt{S_{t} m_{0}} v_{t}^{\text {rel }}
\end{aligned}
$$

where, $\varepsilon$ is the coefficient of recovery; $S_{n}$ is normal stiffness, N/m; $m_{0}$ is the equivalent mass, $\mathrm{kg} ; v_{n}{ }^{\text {rel }}$ is the normal component of the relative velocity of the contact point, $\mathrm{m} / \mathrm{s} ; v_{t}^{\text {rel }}$ is the tangential component of the relative velocity of the contact point, $\mathrm{m} / \mathrm{s}$.

In the model, the tangential force $\left(\mu_{s} F_{n}\right)$ is related to the friction force ${ }^{[17]}$, where $\mu_{s}$ is the static friction factor. The moment of the contact surface can be expressed by the rolling friction force, that is

$$
T_{i}=-\mu_{r} F_{n} R_{i} \omega_{i}
$$

where, $\mu_{r}$ is the coefficient of rolling friction; $R_{i}$ is the rolling radius, $\mathrm{m} ; \omega_{i}$ is the unit angular velocity of the particle at the contact point, $\mathrm{rad} / \mathrm{s}$.

Based on Hertz-Mindlin contact model, its simulation parameters can be divided into two categories, namely, material property and interaction parameters. The material property parameters include shape, density, Poisson's ratio, and shear modulus. The interaction parameters consist of the coefficient of restitution, the coefficient of static friction, and the coefficient of rolling friction.

\subsubsection{Corn model}

The shape of corn kernels (Longdan No.5, China) varies from each other. To make the experimental and simulation results consistent, the characteristics of corn kernels was classified. One thousand corn kernels were selected randomly to classify as horse tooth, spherical cone, spherical, oblate, and irregular shape. The statistical results show their number percentages are 39.7\%, 42.7\%, $8.7 \%, 6.0 \%$ and $2.9 \%$, respectively. Corn kernel size followed a normal distribution with a variance of 0.05 . Five shape kinds of corns that are close to the average size value were selected to build a 3D corn model using the technology of slicing modeling ${ }^{[18]}$. The model of corn that is constructed by filling overlapping spheres has been studied and proven to be useful ${ }^{[19,20]}$. Therefore, five shape kinds of corn discrete element model were filled with varied spherical diameters as fully as possible, as shown in Figure 2.

\subsubsection{Bulk density}

Due to the inevitable differences between the actual corn kernels and the simulation models, especially the obvious difference in bulk density, to make the simulation results more realistic, the volume of five corn shape kinds (horse tooth, spherical cone, spheroid, oblate shape, and irregular shape) was adjusted to match their actual volume, respectively. $50 \mathrm{~mL}, 250 \mathrm{~mL}, 500 \mathrm{~mL}$ measuring cylinders were used to measure their volume. The volume of the corn model was changed to match the height of corns. The height of five shape kinds of corn kernel in measuring cylinder before and after adjustment are shown in Figure 3. To verify the volume of mixed five shape kinds of corn kernel models, five corn shape kinds were mixed by 13:14:3:2:1 percentage and put into two containers (organic glass box, aluminum cylinder) to compare the corn height between actual and simulation corns, as shown in Figure 4. The organic glass box (length $\times$ width $\times$ height) is $100 \mathrm{~mm} \times 60 \mathrm{~mm} \times 110 \mathrm{~mm}$, and it consists of the main box, and the baffle. The aluminum cylinder (inner diameterxheight) is $54 \mathrm{~mm} \times 300 \mathrm{~mm}$. Figure 5 shows that the optimized corn discrete element models and the size, which will be used in all subsequent simulations.

\subsubsection{Parameters}

Referring to ASAE Standards ${ }^{[21]}$ and literature ${ }^{[22]}$, Poisson's ratio of the corn kernel is 0.4 , and the shear modulus is $1.37 \times 10^{8} \mathrm{~Pa}$ The density calculated through the drainage method is $1180 \mathrm{~kg} / \mathrm{m}^{3}$. The interaction parameters of HSCM consist of the coefficient of restitution, the coefficient of static friction, and the coefficient of rolling friction ${ }^{[23]}$. In general, the corn coefficient of restitution is the ratio between the relative rebound and impact velocities when one moving corn kernel impact another stationary one, which is $0.37^{[24]}$. The coefficient of static and rolling friction has a critical influence on particle-discharge behavior ${ }^{[25]}$. However, they are relatively difficult to measure directly. Due to the roughness of the corn kernel surface and the difference in center of gravity between simulation models and actual corn kernels, their coefficient of static and rolling friction have a large gap. This paper draws on the methods from the literature ${ }^{[4]}$ to calibrate the coefficient of static and rolling friction of corn commonly grown in Gansu for investigating the effect of that on the formation process of repose angle of corn kernels. Cron kernel's other property and interaction parameters are listed in Table 1. 


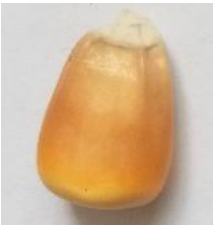

Horse tooth

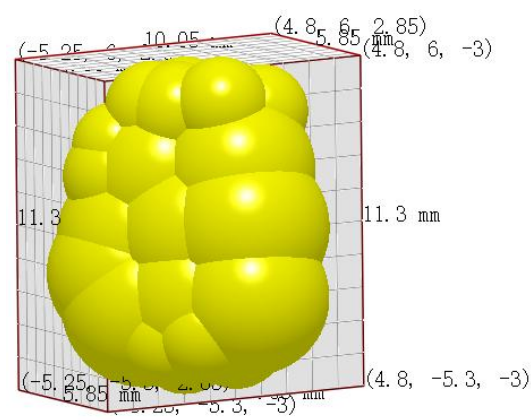

Horse tooth

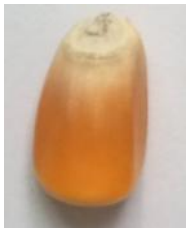

Spherical cone

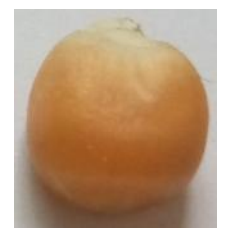

Spheroid

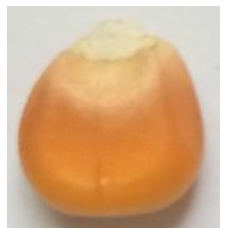

Oblate shape

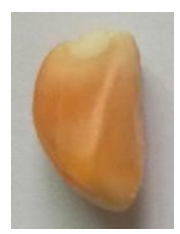

Irregular shape

a. Actual corn kernel shapes

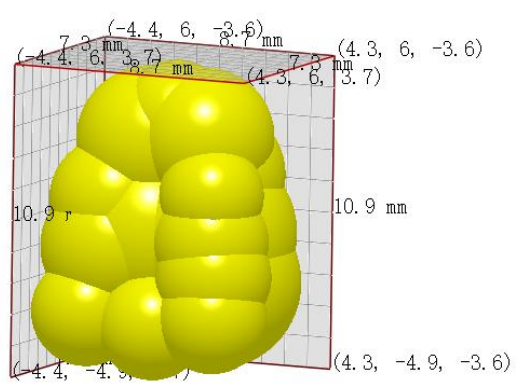

Spherical cone

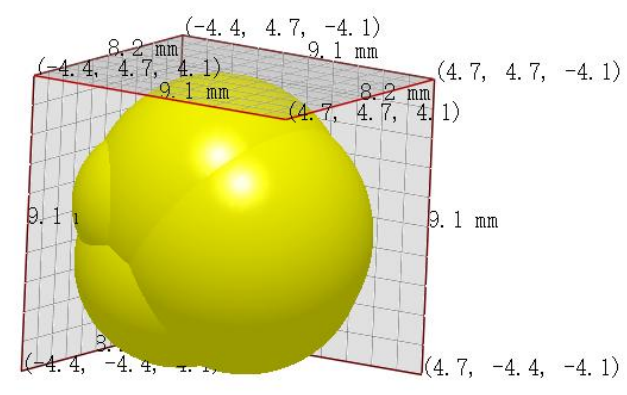

Spheroid

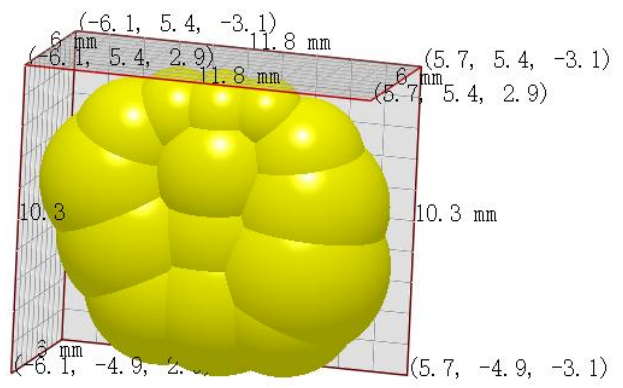

Oblate shape

b. Initial discrete element models of the corn kernel

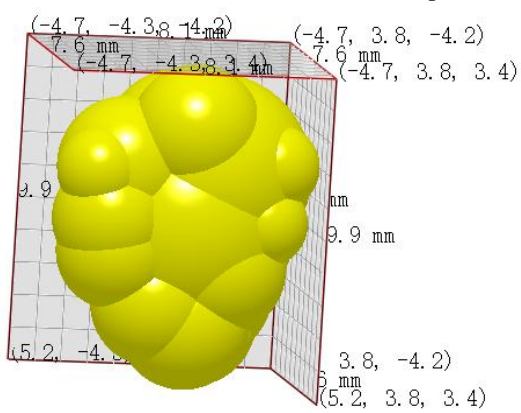

Irregular shape

Figure 2 Corn kernel and the discrete element models

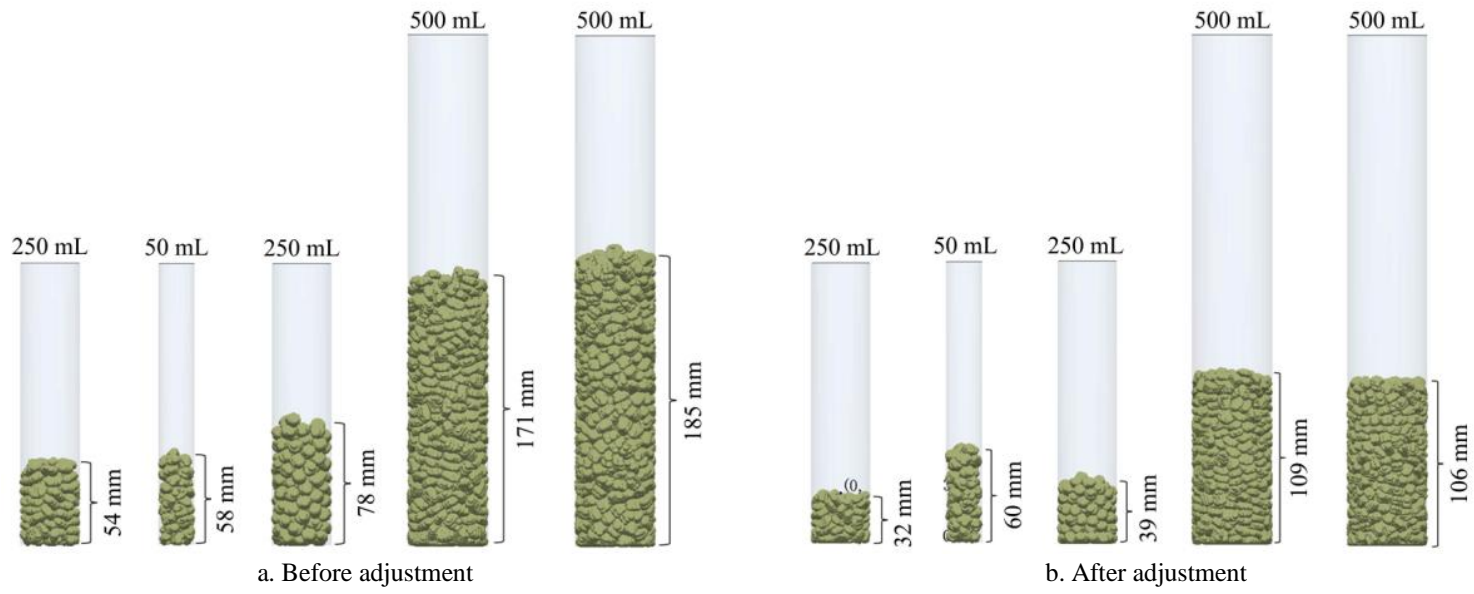

Figure 3 The volumes of five shape kinds of corns

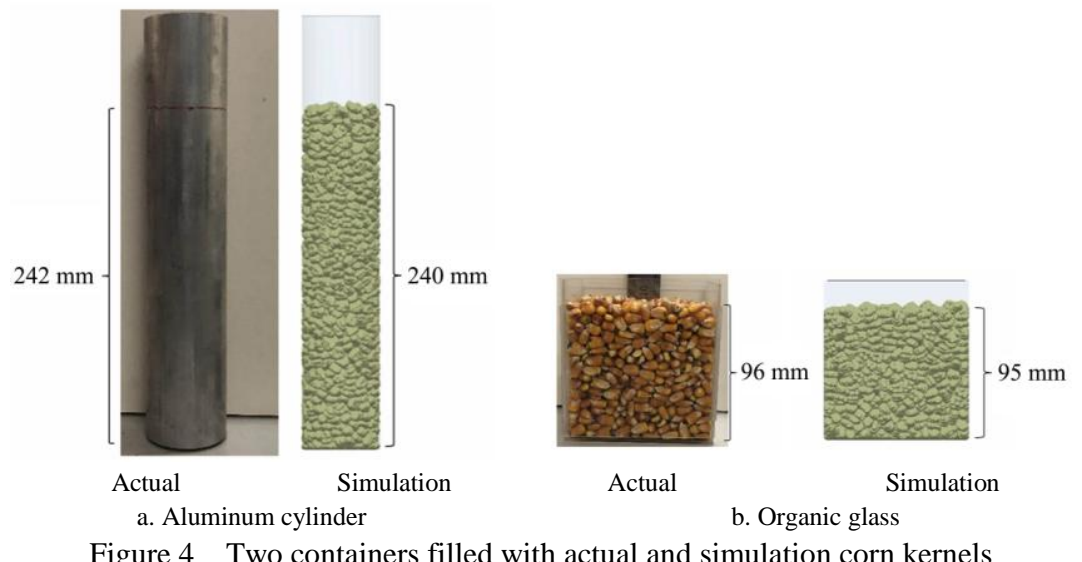

Figure 4 Two containers filled with actual and simulation corn kernels 


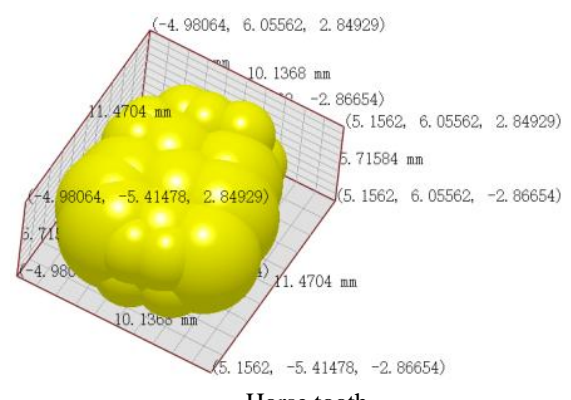

Horse tooth

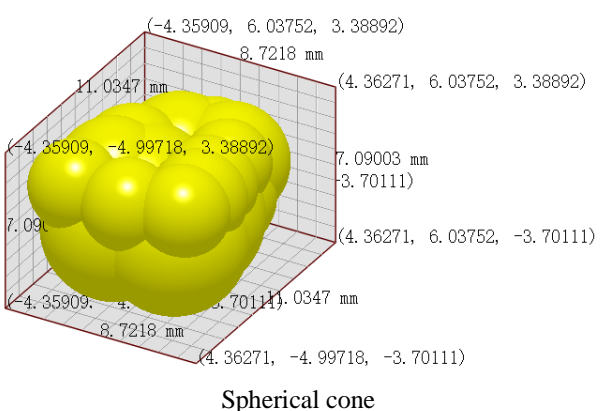

Spherical cone

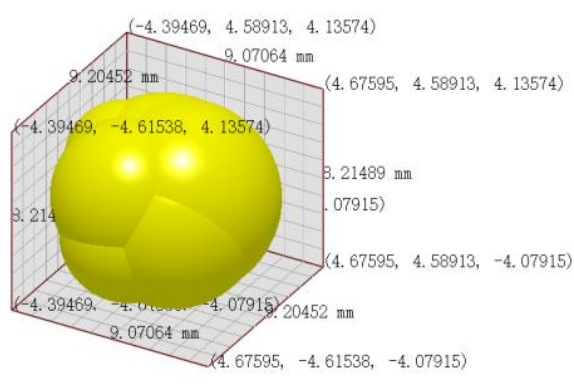

Spheroid

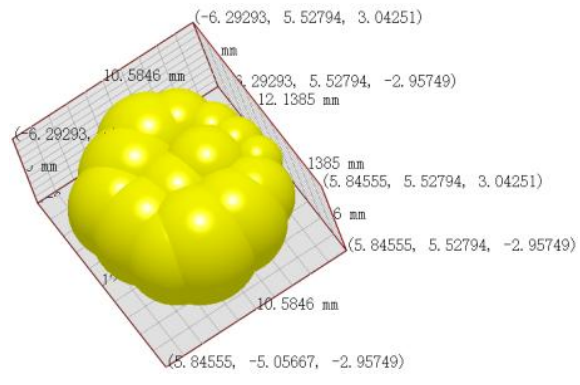

Oblate shape

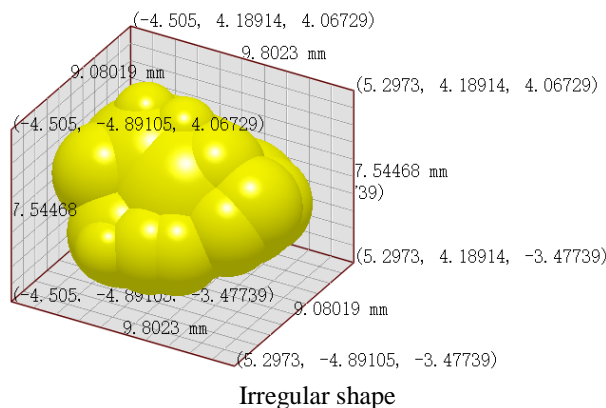

Irregular shape

Figure 5 Optimized discrete element models of the corn kernel

Table 1 Other parameters used in the DEM simulation

\begin{tabular}{lc}
\hline \multicolumn{1}{c}{ Parameters } & Value \\
\hline Poisson ratio of aluminum & 0.34 \\
Shear modulus of aluminum/Pa & $2.5 \times 10^{10}$ \\
Aluminum density $/ \mathrm{kg} \cdot \mathrm{m}^{-3}$ & 2700 \\
Poisson ratio of organic glass & 0.35 \\
Shear modulus of organic glass $/ \mathrm{Pa}$ & $1.3 \times 10^{9}$ \\
Organic glass density/ $\mathrm{kg} \cdot \mathrm{m}^{-3}$ & 1200 \\
Coefficient of restitution between corn kernel and aluminum & 0.729 \\
Coefficient of restitution between corn and organic glass & 0.621 \\
Coefficient of static friction between corn and organic glass & 0.459 \\
Coefficient of static friction between corn and aluminum & 0.342 \\
Coefficient of rolling friction between corn and organic glass & 0.0931 \\
Coefficient of rolling friction between corn and aluminum & 0.0515 \\
\hline
\end{tabular}

\section{Results and discussion}

\subsection{Formation of repose angle}

\subsubsection{Actual repose angle}

The formation process of repose angle of corn kernels in the organic glass box is as follows: the baffle is pulled upwards at the speed of $20 \mathrm{~mm} / \mathrm{s}$, and the population of corn kernels from top to bottom flow down. When the corn kernels are stable, the angle between the corn population slope and the horizontal plane is the repose angle. The formation process of repose angle of corn kernels in the aluminum cylinder is as follows: the bottom of the cylinder is fitted to the desktop, then the cylinder is pulled up at a speed of $20 \mathrm{~mm} / \mathrm{s}$. The corn population naturally accumulates. The angle between the population slope and the horizontal plane is the repose angle. As the population is conical accumulation, to get more accurate results, the repose angle images are recorded from cross-section direction and marked angle from $x$ direction and $y$ direction respectively, and their average value is the repose angle. Each experiment was conducted five times.

The marking process of repose angle is as follows: firstly, the image was imported into Photoshop for horizontal correction and clipping and saved in JPG. Then it was introduced into CAXA electronic drawing board. With the reference of corn population boundary drawn the horizontal line and the inclined boundary line with the line command, and the angle between the two lines was the repose angle we needed. The actual repose angle under the organic glass box, the aluminum cylinder, is shown in Figure 6, Figure 7, respectively. The statistical results are shown in Table 2.

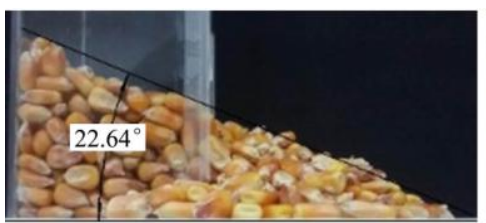

a. Group 1

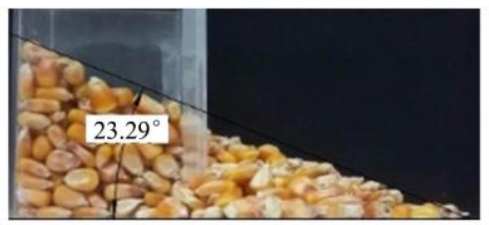

b. Group 2

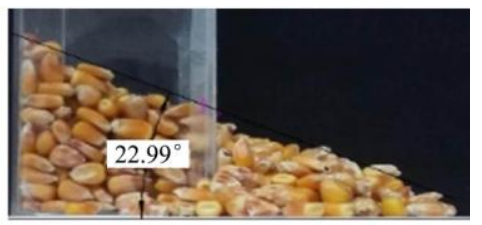

c. Group 3

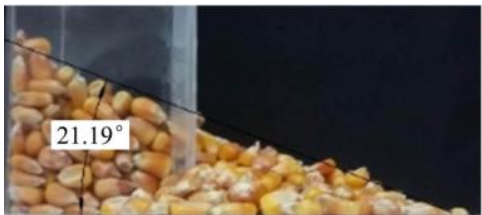

d. Group 4

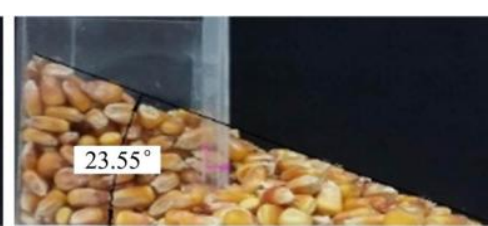

e. Group5

Figure 6 Actual repose angle under the organic glass box 


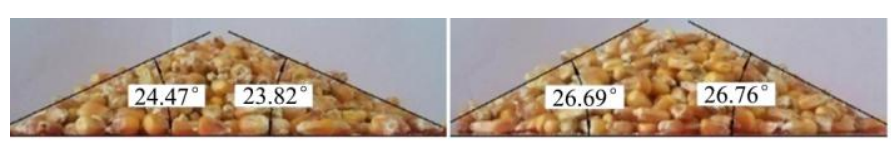

$x$ direction

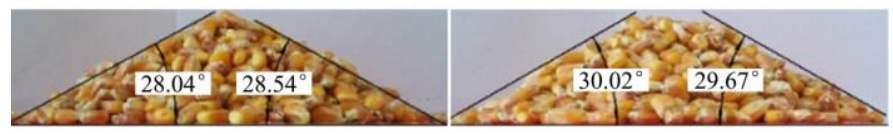

$x$ direction a. Group 1

$y$ direction

$y$ direction

c. Group 3

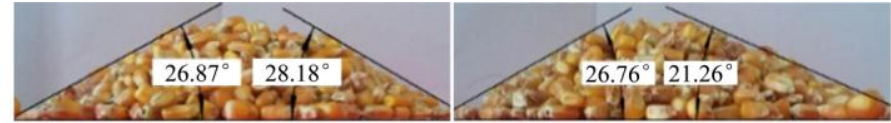

$x$ direction

b. Group 2

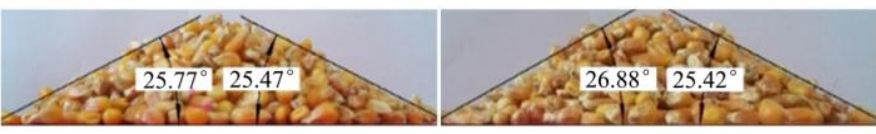

$x$ direction

d. Group 4

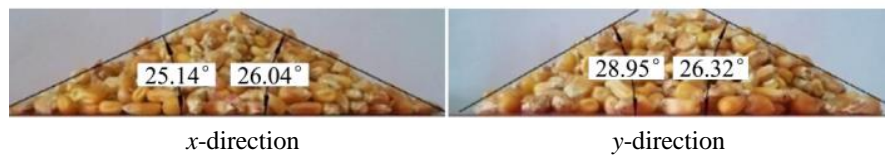

e. Group 5

Figure 7 Actual repose angle under the aluminum cylinder

Table 2 Angles of repose in the experiment $\left({ }^{\circ}\right)$

\begin{tabular}{cccccccc}
\hline \multicolumn{1}{c}{ Container } & \multicolumn{4}{c}{ Repose angle } & \multicolumn{3}{c}{$\begin{array}{c}\text { Average } \\
\text { value }\end{array}$} \\
\hline Organic glass box & 22.64 & 23.29 & 22.99 & 21.19 & 23.55 & 22.73 & 0.93 \\
Aluminum cylinder & 25.44 & 25.77 & 29.07 & 25.89 & 26.61 & 26.56 & 1.47 \\
\hline
\end{tabular}

From Table 2, the average repose angle under the organic glass box, the aluminum cylinder is $22.73^{\circ}, 26.56^{\circ}$, respectively.

3.1.2 Simulation repose angle

(1) Simulation arrangement

The repose angle related to the material properties is a macroscopic-characterizes parameter, affecting the flow of granular materials. The devices include the organic glass box, and aluminum cylinder is used to carry out the simulation experiments. Generation of corns repose in the aluminum cylinder, organic glass box is shown in Figures 8 and 9, respectively.

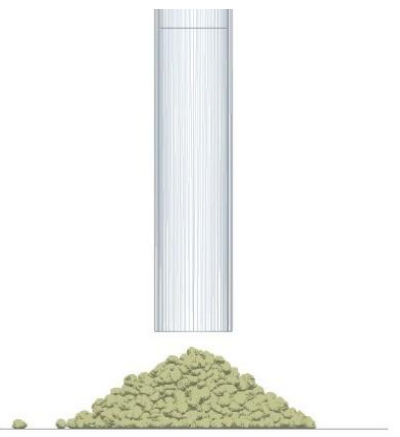

a. Main view

Figure 8 Generation of simulation repose in aluminum cylinder

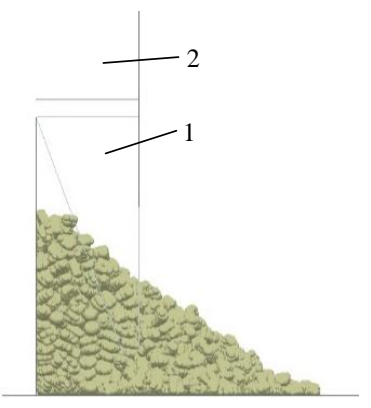

1. Main box 2. Baffle a. Main view b. Top view
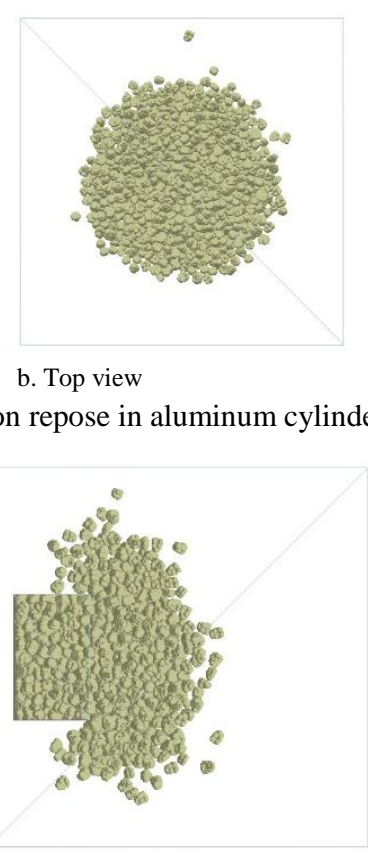

b. Top view
Figure 9 Generation of simulation repose in organic glass

The formation process of repose angle in the aluminum cylinder is as follows: firstly, corn models are generated in $0.83 \mathrm{~s}$.
Secondly, the aluminum cylinder goes up at a speed of $20 \mathrm{~mm} / \mathrm{s}$, and corn models start to fall and make sliding and rolling with each other under gravity. Finally, Corn models form a cone, and the bottom angle of that is the repose angle. The formation process of repose angle in the organic glass box is as follows: firstly, corn models are generated in $0.59 \mathrm{~s}$, the baffle is pulled upwards at a speed of $20 \mathrm{~mm} / \mathrm{s}$, and corn models start to drop to the side under gravity. Corn models form a sloped body, and the bottom angle is the repose angle in the organic glass box.

The level of factors is determined through pre-experiments. To get the stable repose angle of corn models, Each experiment was conducted five times. The experimental simulation arrangements are shown in Table 3.

Table 3 Simulation experiment arrangement

\begin{tabular}{ccc}
\hline No. & Coefficient of static friction & Coefficient of rolling friction \\
\hline 1 & 0.5 & 0.09 \\
2 & 0.3 & 0.05 \\
3 & 0.1 & 0.01 \\
\hline
\end{tabular}

(2) Results and regression analysis

The protractor in EDEM software is used to measure the simulation repose angle. As the three-point of the protractor need to connect to the corn model's center of mass and the corn model is irregular, it is likely to choose $\angle \mathrm{AFC}$ or $\angle \mathrm{AED}$ in Figure 10 , resulting in certain errors. The calculation results show that the angle error range is $-0.038^{\circ}$ to $0.404^{\circ}$ when the slice distance $A B$ is $20 \mathrm{~mm}$, and it is relatively small. Therefore, the angle error can be ignored.
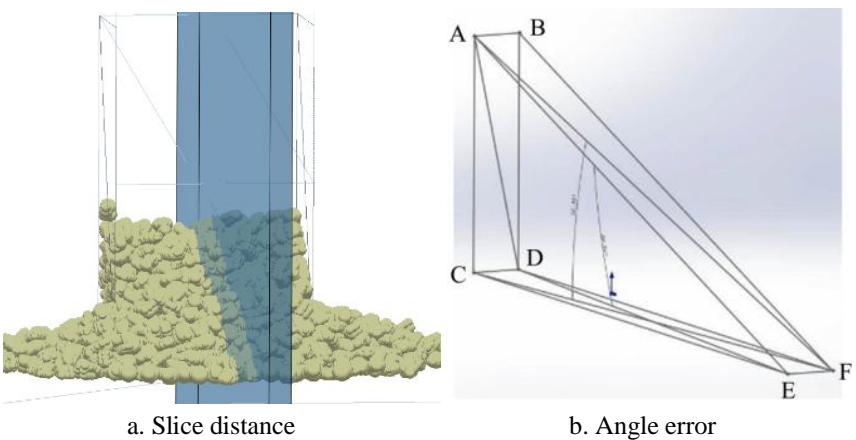

Figure 10 Slice measurement of repose angle

According to the experimental simulation arrangement in Table 3, the experiments were carried out. The experiment results are shown in Table 4. 
Table 4 Simulation experiment results

\begin{tabular}{ccccccccc}
\hline & \multirow{2}{*}{$\begin{array}{c}\text { Coefficient } \\
\text { of static } \\
\text { friction } x_{1}\end{array}$} & $\begin{array}{c}\text { Coefficient } \\
\text { of rolling } \\
\text { friction } x_{2}\end{array}$ & $\begin{array}{c}\text { Repose angle } \\
\text { under organic } \\
\text { glass box } y_{1}\end{array}$ & \multicolumn{3}{c}{$\begin{array}{c}\text { Repose angle under the } \\
\text { aluminum cylinder } y_{2} /\left(^{\circ}\right)\end{array}$} \\
\cline { 6 - 9 } & & 0.09 & 43.15 & 37.46 & 39.71 & 34.25 & 41.04 \\
\hline 1 & 0.5 & 0.05 & 37.75 & 33.63 & 34.25 & 34.85 & 36.64 \\
3 & & 0.01 & 29.59 & 32.65 & 32.55 & 34.02 & 33.54 \\
\hline 4 & & 0.09 & 36.84 & 38.41 & 38.35 & 35.57 & 34.47 \\
5 & 0.3 & 0.05 & 32.16 & 33.19 & 32.12 & 36.41 & 32.45 \\
6 & & 0.01 & 28.37 & 34.97 & 31.43 & 31.75 & 29.97 \\
\hline 7 & & 0.09 & 22.45 & 29.26 & 26.05 & 28.19 & 27.02 \\
8 & 0.1 & 0.05 & 22.41 & 27.35 & 27.56 & 25.26 & 25.58 \\
9 & & 0.01 & 18.47 & 23.10 & 20.24 & 22.05 & 19.46 \\
\hline
\end{tabular}

Based on the simulation results from Table 4 , two binary quadratic regression equations between two factors and the repose angle were established, respectively, as shown in Equations (6) and (7). When the actual repose angles taken as $y_{1}$ and $y_{2}$ were substituted into Equations (6) and (7), respectively, the coefficient of static friction $x_{1}$, and the coefficient of rolling friction $x_{2}$ were calculated.

$$
y_{1}=11.03+76.63 x_{1}+78.67 x_{2}+299.38 x_{1} x_{2}-87.17 x_{1}^{2}-601.04 x_{2}^{2} \text { (6) }
$$$$
y_{2}=13.55+85.85 x_{1}+88.81 x_{2}-46.64 x_{1} x_{2}-96.32 x_{1}^{2}-79.95 x_{2}^{2}
$$

where, $y_{1}$ is the repose angle under the organic glass box; $y_{2}$ is the repose angle under the aluminum cylinder; $x_{1}$ is the coefficient of static friction; $x_{2}$ is the coefficient of rolling friction.

There are four groups of solutions, including the first group: $x_{1}$ is 0.79 and $x_{2}$ is 0.508 , and the second group: $x_{1}$ is 0.11 and $x_{2}$ is 0.064 , and the third group: $x_{1}$ is 0.70 and $x_{2}$ is 0.003 , and the fourth group: $x_{1}$ is 0.19 and $x_{2}$ is 0.002 . With references, the coefficient of static friction of corns is generally less than 0.5. Thus, the solutions of the first group and the third group do not meet. To obtain a more accurate coefficient of static friction and the coefficient of rolling friction, the second group, and the fourth solutions need to be verified further.

(3) Solution verification

The verification of repose angle under organic glass box is shown in Figure 11. The repose angle under the second group is $23.75^{\circ}$, and its relative error compared to the actual value $\left(22.73^{\circ}\right)$ is $4.29 \%$. In contrast, the repose angle under the fourth group is $22.64^{\circ}$, and its relative error is $0.38 \%$.

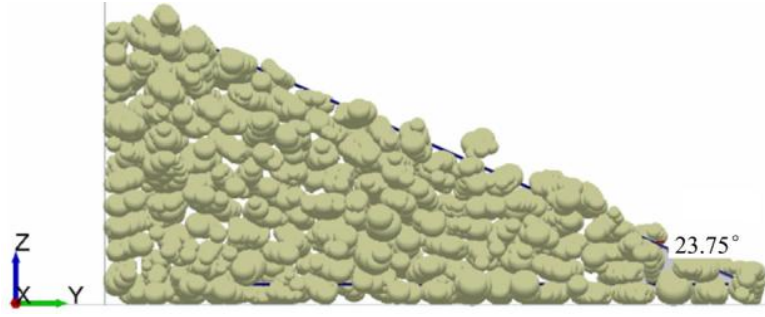

a. The second group solution

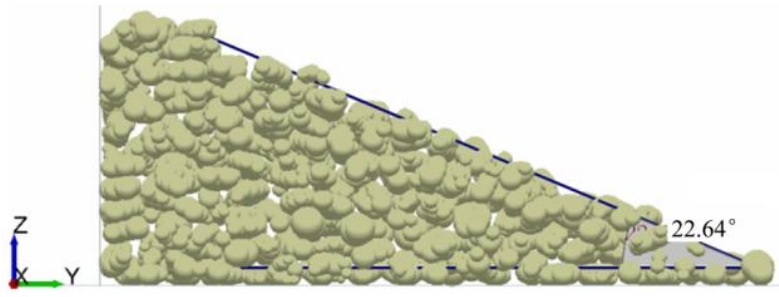

b. The fourth group solution

Figure 11 Verification of repose angle under organic glass box

The verification of repose angle under the aluminum cylinder is shown in Figure 12. The repose angle under the second group solution is $27.59^{\circ}$ and its relative error compared to the actual value $\left(26.56^{\circ}\right)$ is $3.73 \%$. In comparison, the verification repose angle under the fourth group is $25.73^{\circ}$, and its relative error is $3.13 \%$.

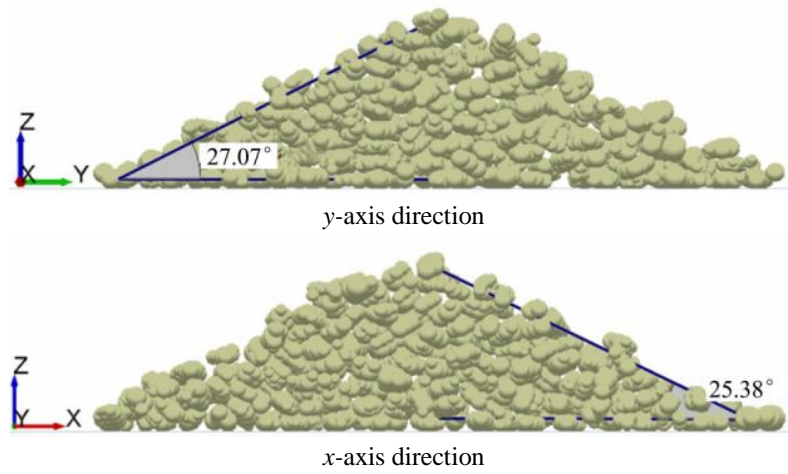

a. The second group Solution

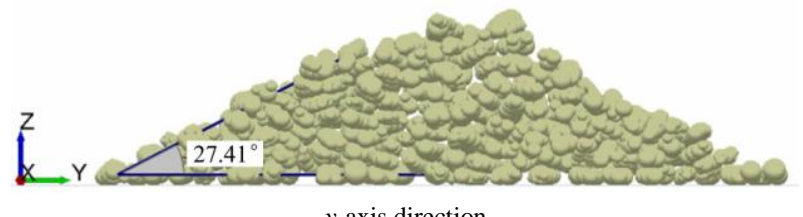

$y$-axis direction

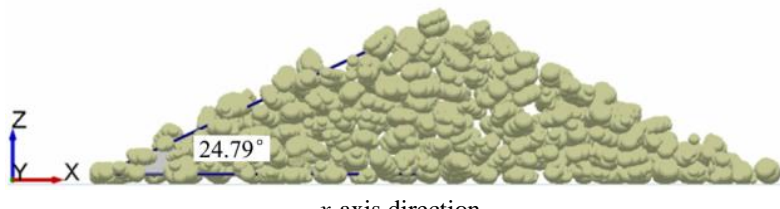

$x$-axis direction

b. The fourth group solution

Figure 12 Verification of the repose angle under the aluminum cylinder

Therefore, the repose angle under the fourth group solution is close to the actual value of repose angle. This is that through calibration the coefficient of static friction is 0.19 , and the coefficient of rolling friction is 0.002 .

\subsection{Effects of two factors on the rotational kinetic energy}

To analyze the effect of SF and RF on the flow rate of corn models, respectively, their rotational kinetic energy during forming repose angle was recorded through changing SF or RF.

\subsubsection{Coefficient of static friction}

The effect behavior of the coefficient of static friction on the rotational kinetic energy is observed in Figures 13.

From Figure 13, when the coefficient of rolling friction is 0.05 , the maximum rotational kinetic energy under the aluminum cylinder is delayed by increasing the coefficient of static friction $(0.1,0.3$, and 0.5$)$. In addition, the maximum rotational kinetic energy happens under organic glass box also have certain delays, but their maximum value happen when the coefficient of static friction is 0.3 .

3.2.2 The coefficient of rolling friction

The effects of the coefficient of rolling friction on the rotational kinetic energy are also analyzed, as shown in Figure 14.

From Figure 14, when the coefficient of static friction is 0.3 , the maximum rotational kinetic energy decreases with increasing the coefficient of rolling friction $(0.01,0.05$, and 0.09$)$. When the coefficient of rolling friction is 0.01 , the maximum value of rotational kinetic energy occurs under the aluminum cylinder. However, when the coefficient of rolling friction is 0.05 , the maximum value happens under organic glass box.

The above analysis shows that the relation between the two factors (the coefficient of rolling friction, the coefficient of static friction) and the rotational kinetic energy are not nonlinear. 

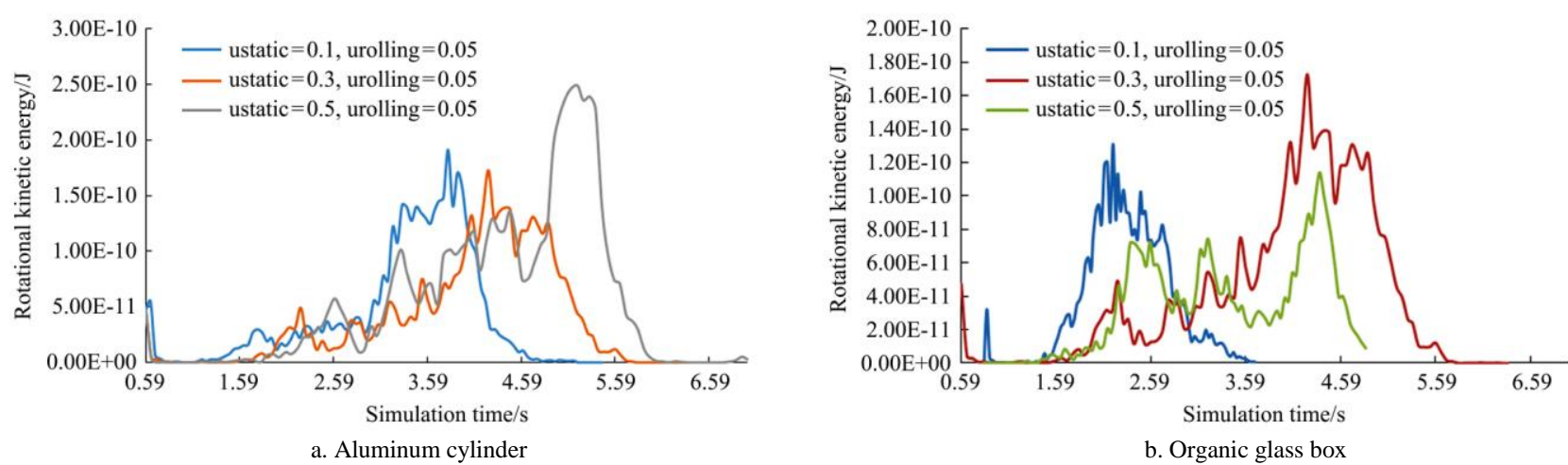

Figure 13 Effect of the coefficient of static friction on rotational kinetic energy
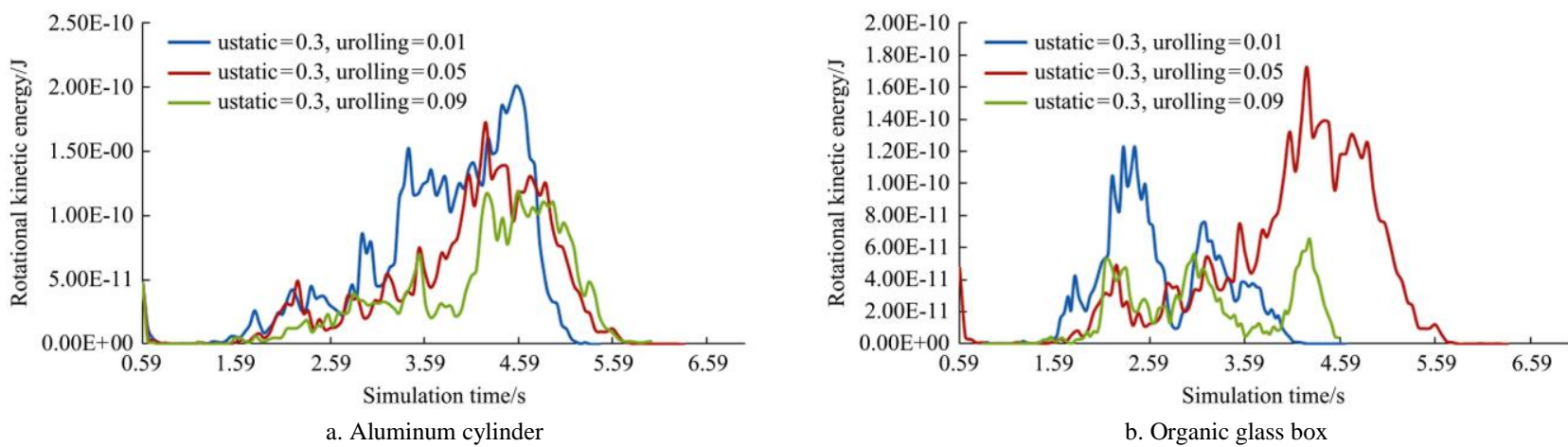

Figure 14 Effect of the coefficient of rolling friction on rotational kinetic energy

\subsection{Effects of two factors on repose angle}

The effect of the coefficient of static and rolling friction on the repose angle is investigated, as shown in Figure 15.

From Figure 15a, the repose angle increases linearly with increasing the coefficient of static friction $(0.1,0.3$ and 0.5$)$ under the organic glass box. However, it increases first and then slows under the aluminum cylinder. This is due to the fact that when corn models accumulate downward from one direction under organic glass box, the coefficient of static friction during the transformation process from potential energy to kinetic energy has a significant limitation on piles accumulation, while the potential energy is converted to kinetic energy from 4 directions under the aluminum cylinder. Therefore, the coefficient of static friction after increasing the direction does not significantly restrict the flow of corn models.

From Figure 15b, it can be seen that the repose angle increases with the increase the coefficient of rolling friction $(0.01,0.05$ and 0.09). Before 0.09 , the repose angle under organic glass box is larger than that under the aluminum cylinder.

\subsection{Effect of two factors on the contact number}

3.4.1 The coefficient of static friction

The effect of static friction coefficient on the contact number

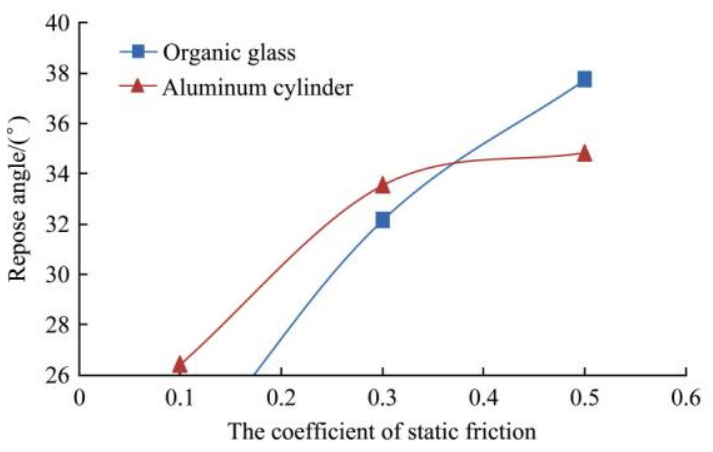

a. The coefficient of static friction between corn models and bottom plate is shown in Figure 16.

The corn population generation time under the organic glass box, aluminum cylinder is $0.59,0.83$, respectively. The initial contact number between corn models and bottom plate under the organic glass box, the aluminum cylinder is 74,37 , respectively. From Figure 16a, when the coefficient of rolling friction is 0.05 , their contact number decreases with increasing the coefficient of static friction $(0.1,0.3$, and 0.5$)$ and the forming time delay. From Figure $16 \mathrm{~b}$, when the coefficient of static friction is 0.1 , the maximum contact number is the biggest.

Therefore, the effect of the coefficient of static friction on the contact number between corns and the bottom plate is remarkable.

3.4.2 The coefficient of rolling friction

The effect of the coefficients of rolling friction on the contact number is shown in Figure 17.

From Figure 17, when the coefficient of static friction is 0.3 , the contact number decreases with increasing the coefficient of rolling friction $(0.01,0.05$, and 0.09). However, the forming time of the repose angle is not obvious. Moreover, the contact number between the bottom plate and corn models is not remarkable.

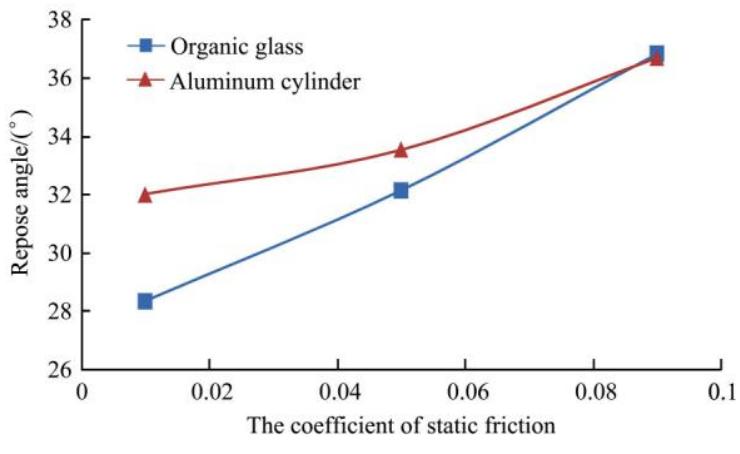

b. The coefficient of rolling friction

Figure 15 Effects of the coefficient of two factors on repose angle 


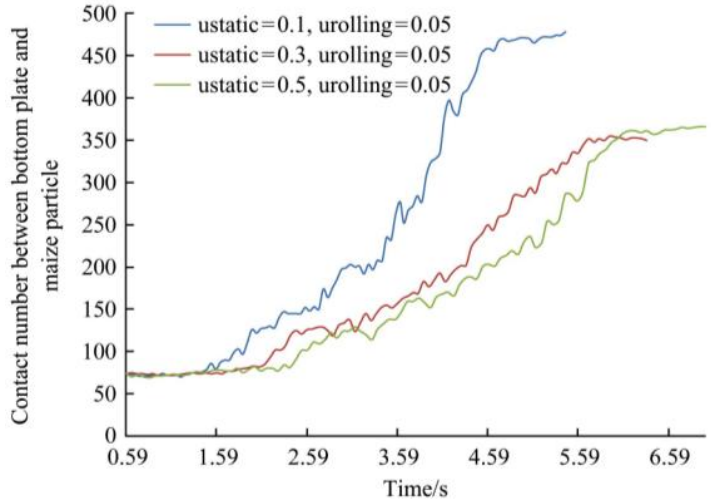

a. Aluminum cylinder

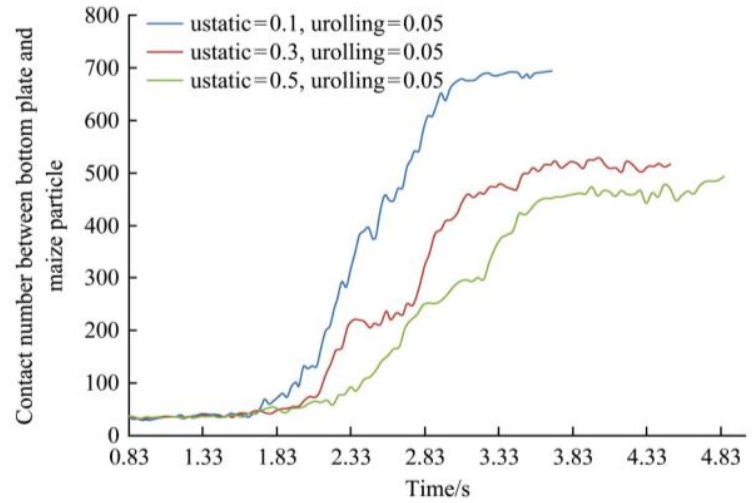

b. Oragnic glass box

Figure 16 Effect of the static friction on the contact number

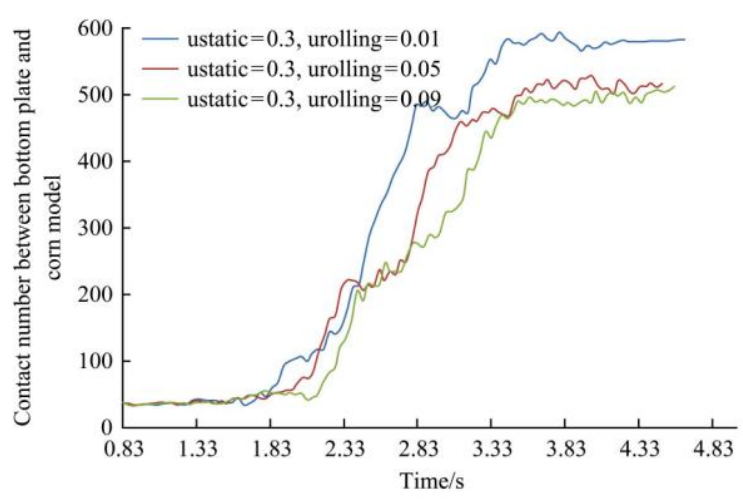

a. Aluminum cylinder

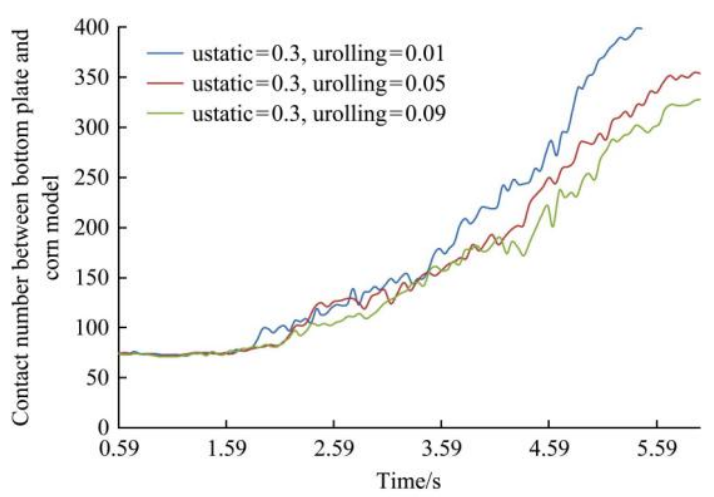

b. Oragnic glass box

Figure 17 Effect of the coefficient of rolling friction on contact number

\subsection{Interaction effect of two factors on the repose angle}

The influence of one factor on rotational kinetic energy, the repose angle, and the contact number was discussed above. Finally, the interaction effect of two factors on the repose angle is analyzed by variance analysis, as shown in Table 5 .

From Table 5, variance analysis results show that the coefficient of static friction and the coefficient of rolling friction all have a significant impact on the repose angle under two containers. Moreover, the interaction effect of two factors has an impact on the repose angle.

Origin Pro2017 was used to generate the changing trend between the repose angle and two factors, as shown in Figure 18.

Table 5 Variance analysis of interaction effect

\begin{tabular}{|c|c|c|c|c|c|c|c|c|c|c|c|c|}
\hline & \multicolumn{6}{|c|}{ Organic glass box } & \multicolumn{6}{|c|}{ Aluminum cylinder } \\
\hline & $\begin{array}{c}\text { The coefficient } \\
\text { of static } \\
\text { friction }\end{array}$ & $\begin{array}{l}\text { The coefficient } \\
\text { of rolling } \\
\text { friction }\end{array}$ & Interaction & Model & Error & $\begin{array}{l}\text { Corrected } \\
\text { total }\end{array}$ & $\begin{array}{l}\text { The coefficient } \\
\text { of static } \\
\text { friction }\end{array}$ & $\begin{array}{c}\text { The coefficient } \\
\text { of rolling } \\
\text { friction }\end{array}$ & Interaction & Model & Error & $\begin{array}{c}\text { Corrected } \\
\text { total }\end{array}$ \\
\hline DF & 2 & 2 & 4 & 8 & 0 & 8 & 2 & 2 & 4 & 8 & 0 & 8 \\
\hline $\begin{array}{l}\text { Sum of } \\
\text { squares }\end{array}$ & 394.9913 & 114.603 & 25.06111 & 534.6554 & 0 & 534.6554 & 394.9913 & 114.603 & 25.06111 & 534.6554 & 0 & 534.6554 \\
\hline Mean square & 197.4956 & 57.30148 & 6.26528 & 66.83192 & & & 197.4956 & 57.30148 & 6.26528 & 66.83192 & & \\
\hline Significance & $* *$ & $* *$ & $*$ & & & & $* *$ & $* *$ & $*$ & & & \\
\hline
\end{tabular}

Note: $* *$ stands for very significant, and $*$ stands for significant.

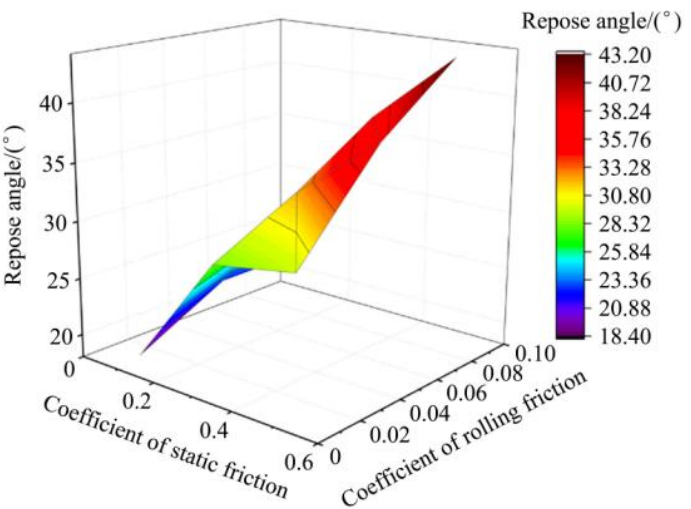

a. Organic glass box

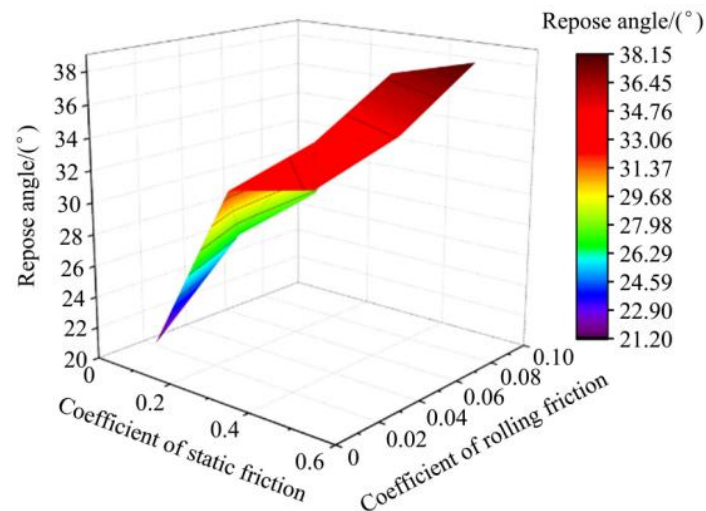

b. Aluminum cylinder

Figure 18 Changing trend of repose angle affected by two factors 
From Figure 18, overall, the repose angle generally increases with the increase of the coefficient of static friction, the coefficient of rolling friction. The repose angle under the organic glass box rapidly increases during the range of the coefficient of static friction (0.2-0.4), and after 0.4 , the value increases slowly. Two factors have a great influence on the repose angle under the Aluminum cylinder.

\section{Conclusions}

Two containers were used to form the simulation repose angle, taking the coefficient of static friction, and rolling friction as an independent and repose angle as the dependent value. Based on this research, the specific conclusions can be drawn as follows:

(1) On the basis of simulation results, two binary quadratic regression equations between the repose angle and the coefficient static friction and rolling friction were established. The coefficient of static friction, rolling friction is 0.19 and 0.002 after verification, respectively.

(2) The influence of the coefficient of static friction, or rolling friction on rotational kinetic energy, the repose angle, and the contact number were discussed in detail. Results show that the relation between the two factors and the rotational kinetic energy are not nonlinear. The coefficient of static friction after increasing the direction does not significantly restrict the flow of corn models. The effect of the coefficient of static friction on the contact number between corns and the bottom plate is remarkable. In contrast, the effect of the coefficient of rolling friction on the contact number is not remarkable.

(3) Variance analysis results show the coefficient of static and rolling friction all significantly impact the repose angle. Moreover, their interaction effect has an impact on the repose angle.

\section{Acknowledgements}

This work was supported by the Excellent Ph.D. Dissertation of Gansu Agricultural University (YB2020003) and the Chinese Natural Science Foundation (52065004).

\section{[References]}

[1] Wei H, Nie H, Li Y, Saxén H, Yu Y. Measurement and simulation validation of DEM parameters of pellet, sinter and coke particles. Powder Technology, 2020; 364(15): 593-603.

[2] Zeng Z W, Ma X, Cao X L, Li Z H, Wang X C. Critical review of applications of discrete element method in agricultural engineering. Transactions of the CSAM, 2021; 52(4): 1-20. (in Chinese)

[3] Dun G Q, Gao Z Y, Liu Y X, Ji W Y, Mao N, Wu X P, et al. Optimization design of fertilizer apparatus owned arc gears based on discrete element method. Int J Agric \& Biol Eng, 2021; 14(2): 97-105.

[4] Wang Y X, Liang Z J, Zhang D X, Cui T, Shi S, Li K L, et al. Calibration method of contact characteristic parameters for corn seeds based on EDEM Transactions of the CSAE, 2016; 32(22): 36-42. (in Chinese)

[5] Chen H, Zhao S, Zhou X. DEM investigation of angle of repose for super-ellipsoidal particles. Particuology, 2020; 50: 53-66.

[6] Chen J, Gao R, Liu Y P, Zhu H T. Numerical study of particle morphology effect on the angle of repose for coarse assemblies using DEM.
Advances in Materials Science and Engineering, 2019; 2019: 1-15.

[7] Shi L R, Zhao W Y, Sun B G, Sun W. Determination of the coefficient of rolling friction of irregularly shaped maize particles by using discrete element method. Int J Agric \& Biol Eng, 2020; 13(2): 15-25.

[8] Jayasundara C T, Yang R Y, Yu A B, Curry D. Discrete particle simulation of particle flow in IsaMill-effect of grinding medium properties. Chemical Engineering Journal, 2008; 135(1): 103-112.

[9] Zeng Y, Jia F, Meng X, Han Y, Xiao Y. The effects of friction characteristic of particle on milling process in a horizontal rice mill. Advanced Powder Technology, 2018; 29(5): 1280-1290.

[10] Wang L, Li R, Wu B, Wu Z, Ding Z. Determination of the coefficient of rolling friction of an irregularly shaped maize particle group using physical experiment and simulations. Particuology, 2017; 38(6): 185-195.

[11] Han Y L, Jia F G, Tang Y R, Liu Y, Zhang Q. Influence of granular coefficient of rolling friction on accumulation characteristics. Acta Physica Sinica, 2014; 63(17): 174-501.

[12] Lee S, Park J. Standardized friction experiment for parameter determination of discrete element method and its validation using angle of repose and hopper discharge. Multiscale Science and Engineering, 2019; 1(3): 247-255.

[13] Kanakabandi C K, Goswami T K. Determination of properties of black pepper to use in discrete element modeling. Journal of Food Engineering, 2019; 246: 111-118.

[14] Shi L R, Ma Z T, Zhao W Y, Yang X P, Sun B G, Zhang J P. Calibration of simulation parameters of flax seeds using discrete element method and verification of seed-metering test. Transactions of the CSAE, 2019; 35(20): 25-33. (in Chinese)

[15] Peng F, Wang H Y, Fang F, Liu Y D. Calibration of discrete element model parameters for pellet feed based on injected section method. Transactions of the CSAM, 2018; 49(4): 140-147. (in Chinese)

[16] Liu Y, Han Y L, Jia F G, Yao LN, Wang H, Shi Y F. Numerical simulation on stirring motion and mixing characteristics of ellipsoid particles. Acta Physica Sinica, 2015; 64(11): 114-501.

[17] Chen J, Zhou H, Zhao Z, Li Y M, Gong Z Q. Analysis of rice seeds motion on vibrating plate using EDEM. Transactions of the CSAM, 2011 42(10): 79-83, 100. (in Chinese)

[18] Shi L R, Zhao W Y, Wu J M, Zhang F W, Sun W, Dai F, Wang L J. Application of slice modeling technology in finite element analysis of agricultural products. Journal of Chinese Agricultural Mechanization, 2013; 6: 110-112. (in Chinese)

[19] Markauskas D, Ka`cianauskas R, D`ziugys A, Navakas R. Investigation of adequacy of multi-sphere approximation of elliptical particles for DEM simulations. Granular Matter, 2010; 12(1): 107-123.

[20] Markauskas D, Ramírez-Gómez Á, Kačianauskas R, Zdancevičius E. Maize grain shape approaches for DEM modeling. Computers \& Electronics in Agriculture, 2015; 118(C): 247-258.

[21] ASAE Standards S368.4 (R2017): Compression test of food materials of convex shape. ASABE, 2017; pp.592-599.

[22] Boac J M, Casada M E, Maghirang R G, Harner J P. Material and interaction properties of selected grains and oilseeds for modeling discrete particles. Transactions of the ASABE, 2010; 53(4): 1201-1216.

[23] Horabik J, Molenda M. Parameters and contact models for DEM simulations of agricultural granular materials: a review. Biosystems Engineering, 2016; 147: 206-225.

[24] Wang L J, Zhou W X, Ding Z J, Li X X, Zhang C G. Experimenta determination of parameter effects on the coefficient of restitution of differently shaped maize in three-dimensions. Powder Technology, 2015; 284(10): 187-194.

[25] González-Montellano C, Fuentes J M, Ayuga-Téllez E, Ayuga F. Determination of the mechanical properties of corn grains and olives required for use in DEM simulations. Journal of Food Engineering, 2012; 111(4): 553-562. 